\title{
Perception of visual advertising in different media: from attention to distraction, persuasion, preference and memory
}

\author{
Jaana Simola ${ }^{1}$, Jukka Hyönä ${ }^{2}$ and Jarmo Kuisma ${ }^{3}$ \\ ${ }^{1}$ Cognitive Science, Cognitive Brain Research Unit, University of Helsinki, Helsinki, Finland \\ ${ }^{2}$ Department of Psychology, University of Turku, Turku, Finland \\ ${ }^{3}$ Department of Marketing, Aalto University School of Business, Helsinki, Finland \\ *Correspondence: jaana.simola@helsinki.fi
}

Edited and reviewed by:

Lorenza S. Colzato, Leiden University, Netherlands

Keywords: advertising, eye movements, attention, memory, ad format, animation, internet, media

Our everyday visual environment is cluttered with advertisements. We come across them in newspapers, magazines, television, and Internet. They can be static, as in print advertisements, or dynamic, as is often the case with TV and Internet ads. The advertising messages are transmitted into the cognitive and affective systems via visual processes. Rather than being a mere input device, the visual processes both voluntarily and involuntarily control the amount and quality of information that is passed onto further mental processing. The effectiveness of advertising therefore critically depends on its ability to attract visual attention. The advertisements should also retain attention long enough in order to allow sufficient encoding of information into the long-term memory.

This Research Topic reviews and further explores processing of visual advertising. We draw together state of the art research on how different ad properties, such as image statistics, surface size of the ads, presence of human faces or animation, and distance of the ads from the editorial content affect ad processing. Furthermore, new measures are proposed to evaluate the capacity of an advertisement to guide observers' gaze and to evaluate the global scanning behavior related to the ads. The Research Topic also presents novel hypotheses and results concerning the impact of narcissism and alcohol intoxication on ad processing.
Developmental aspects are taken into account by investigating how children interact with online advertisements. The contributions also successfully cover the diversity of media where visual marketing stimuli appear. The studies review and investigate processing of image and text content of print advertisements as well as advertisements in dynamic media, such as in the Internet or in a digital game environment.

Conflict of Interest Statement: The authors declare that the research was conducted in the absence of any commercial or financial relationships that could be construed as a potential conflict of interest.

Received: 26 September 2014; accepted: 06 October 2014; published online: 28 October 2014.

Citation: Simola J, Hyönä J and Kuisma J (2014) Perception of visual advertising in different media: from attention to distraction, persuasion, preference and memory. Front. Psychol. 5:1208. doi: 10.3389/fpsyg.2014.01208

This article was submitted to Cognition, a section of the journal Frontiers in Psychology.

Copyright (๑) 2014 Simola, Hyönä and Kuisma. This is an open-access article distributed under the terms of the Creative Commons Attribution License (CC BY). The use, distribution or reproduction in other forums is permitted, provided the original author(s) or licensor are credited and that the original publication in this journal is cited, in accordance with accepted academic practice. No use, distribution or reproduction is permitted which does not comply with these terms. 